\title{
TOL̈LHO
}

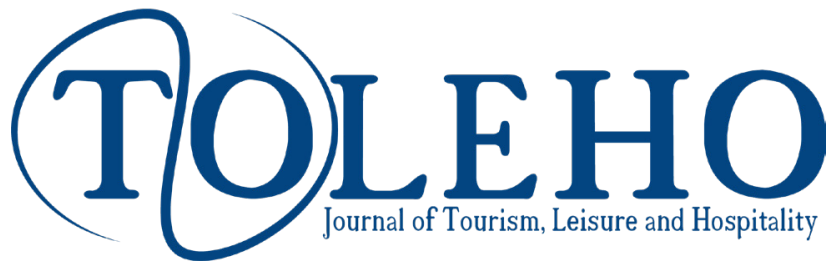

\section{SPACE TOURISM: AN INITIATIVE PUSHING LIMITS}

\author{
Ayşe Meriç Yazici ${ }^{\mathrm{a},}{ }^{,}$, Satyam Tiwari ${ }^{\mathrm{b}}$ \\ ${ }^{\mathrm{a}}$ Blue Marble Space Institute of Science, Washington D.C., U.S.A. \\ ORCID: 0000-0001-6769-2599 / e-mail:ayse.meric@bmsis.org \\ ${ }^{\mathrm{b}}$ Blue Marble Space Institute of Science, Washington D.C., U.S.A. \\ ORCID: 0000-0001-7507-6921 / e-mail:satyam.tiwari@bmsis.org
}

\section{KEYWORDS}

Space tourism

Space giants

Space activities

Space tourists

\begin{abstract}
Since the launch of Sputnik 1, the first artificial satellite, in 1957, the number of participants in space activities has been growing rapidly. Although space tourism is in its early stage, it is estimated that the number of space tourists will increase significantly in the coming years. Space travel has inspired humanity in so many ways that humans are entering a new era where space will be accessible to the general public. Space giants such as SpaceX, Virgin Galactic, Blue Origin, Orion Span and others are making new attempts to open a new page in the field of space activities by introducing the concept of space tourism to the public. In this article, a brief is made on the concept of space tourism, the history of human space travel, and the initiatives developed by companies like SpaceX and Virgin Galactic to make commercial space travel possible. In this article, the definition of Space tourism has been expanded into three subcategories: Sub-orbital space tourism, Orbital space tourism and Beyond Earth orbit Tourism, where companies such as SpaceX and Space Adventures Ltd push their limits. With an anticipated jump in the future of Spacetourism sector, this article demographically represents how people of people of different age group from U.S.A are excited to involve with this activity.
\end{abstract}

\section{Introduction}

Throughout history, man has always been interested in exploring and travelling to new and exciting locations. Ever since the onset of space age, the possibility of public space flights has been an unannounced agenda for the nations travelling in space. Space travel may be the next reasonable step for tourists. Space tourism aims at offering accessibility of exciting locations for adventure and recreational experience. A space tourist will thus become a person who travels to space for adventure and recreational experiences (Annadurai et al., 2011).

Although travelling to extra-terrestrial destinations, visiting other planets and being in an anti-gravity environment might seem like a dream, borders are vanishing and the impossible is becoming possible with the rapid advancement of technology. Space tourism offers individuals a chance to experience space activities (Civelek and Türkay, 2019).

Space tourism is not really a new idea after Apollo 11's first landing on the Moon in 1967. Today, space tourism has become cheaper and safer with the development of new Technologies (Pásková et al., 2021). In future, it is highly anticipated that corporations like SpaceX, Virgin Galactic, Orion Span, etc. will introduce new techniques to avail space tourism to a wide range of customers at the affordable price. Space tourism as such, will provide new prospects and ideas to future generations to indulge with space activities.

Studies have forecasted that in upcoming decades, commercial space tourism is going to foresee a hike in its market revenue by approximately 4 folds. With such a market, space tourism sector will not only be limited to sub-orbital flight types but also orbital and space tourism beyond the earth can be visioned.

This article aims to provide a generalised idea of space tourism and the brief of the innovative ideas which are particularly being developed by SpaceX and Virgin Galactic to make space tourism accessible to the general public.

\section{Space Travel}

\subsection{History of Space Travel}

Space travel has always fascinated mankind. However, the idea of space travel is not new, the perception of space travel has come all the way along from ancient history to the modern era. The first few evidence of human space travel from earth to several worlds like Pitriloka, Brahmaloka, Devaloka can be found in the ancient hindu sagas (Goswami, 2017).

${ }^{*}$ Corresponding Author.

Received 16.01.2021; Received in revised form 03.02.2021; Accepted 07.02.2021 This article is licensed under a Creative Commons Attribution 4.0 International License. e-ISSN: 2687 - 3737 / @ 2021 The Authors. Published by Anadolu University. http://dx.doi.org/10.48119/toleho.862636 
After Galileo Galilei invented the telescope in 1609, people started to see the universe in detail, and principles of cosmos were unveiled. People realized that the Earth was not the centre of the universe, but there are other planets with their satellites orbiting around themselves while they were revoling around the Sun. Later on, mankind was introduced to prominent figures such as Chris Gainor with his magnificent and inspiring articles on space; Robert Goddard and Hermen Oberth creating the first thrill in space researches leading to unveil mysteries of cosmos, (Gainor, 2008) Konstantin Tsiolkovsky the founder of rocket science and an inspiration to space elevator (Yazici, 2020), and Patrick Collins constantly making his studies on the space tourism itself (Danov, 2020). Impressions of space tourism in 20th and 21st centuries are presented in Table 1.

Space tourism is a dynamic space activity with a wider scope, due to its four main factors, as stated below (Chang, 2015);

1. It has a purpose of its own

2. It is a way to meet goals in other areas

Table 1. Impressions of space tourism in 20th and 21st centuries

\begin{tabular}{|c|c|}
\hline Years & Impressions \\
\hline 1954 & oomas Cook guaranteed to provide tickets for a commercial flight to the Moon (Eilingsfeld and Abitzsch, 1993). \\
\hline 1961 & $\begin{array}{l}\text { The first astronaut flew to the Earth's orbit. However, space tourism was an immature idea in state organizations } \\
\text { back then. However, the term 'Space Tourism' was first used at that time (Chang, 2015). The President of Pan Am } \\
\text { called ABC TV network and announced that they were planning to accept booking for future moon flights. When } \\
\text { Pan Am shot down the } 1971 \text { programme; it had already received some } 93.000 \text { applications. }\end{array}$ \\
\hline
\end{tabular}

1970 For a sub-orbital space tourism shuttle, a vehicle called VolksRocket X-3. This controversial German project was one of the first completely private rocket development programmes. The project was initiated by Lutz Kayser - a German aviation engineer developing an innovative modular design enabling a low-cost rocket culster for a multi-staged orbit rocket. In 1978, a group studied the purchase of a fifth shuttle and the possibility of using it with a consortium like original COMSAT (HobbySpace, 2014).

1981 Robert Truax designed a reusable VolksRocket X-3 (Arriba One or Skycycle X-3) (Chang, 2015).

1986 The Challenger disaster was a harsh warning against space flight activities. After this incident, a book on space flight by Ashford and Collins was published; however, space tourism was soon recognized as a business (Ashford and Collins, 1990).

1990 Space Transportation Association (STA) was founded. 1992-1993: Space Transportation Association caused NASA to think over reusable space transportation vehicles including the ones to be used in space tourism. 1993-1994: Japanese Rocket Society published magazines dedicated to space tourism (Chang, 2015).

1997 Space Dev was founded. 1998: Space Adventures Ltd became the first company working with private individuals and citizens who are willing to go to space. 1999: XCOR Aerospace and Bigelow Aerospace were established during the efforts to place a private space station within the orbit (Stimac, 2020).

2000 Soyuz TM-30 was launched by Mir Corp for a manned mission and it became the first privately funded space station exploration (Spaceref, 2000).

2001 Dennis Tito, an American businessman, became the first space tourist travelling to space in a Russian Soyuz spacecraft, who paid to the International Space Station (Wall, 2011).

2004 A Civilian Space Exploration Team became the first amateur organization to send a GoFast rocket into space (Space Frontier Foundation, 2004). On June 21, 2004, Mike Mevill piloted SpaceShipOne- a custom-built rocket vehicle (Coren, 2004). On June 23, 2004, Commercial Space Launch Amendments Act was signed, and it provided an essential guideline for commercial manned space flight (Grush, 2015).

2006 Bigelow Aerospace developed the rocket to launch the first inflatable space habitat module Genesis (Harding, 2016).

2008 SpaceX’s Falcon 1 was successfully launched (Clark, 2008).

2010 SpaceX was the first non-governmental organization to launch and bring back a space vehicle into orbit. 2012: SpaceX started its Dragon C2+ mission to supply the International Space Station (ISS) (The Telegraph, 2012).

2014 The first commercial mission from China to Moon was started (Clark, 2014).

2015 Blue Origin launched a sub-orbit vehicle called New Shepard into space and successfully brought it back (Foust, 2015).

2016 Blue Origin successfully relaunched the New Shepard into the space after its first launch, in 2015 (Rhian, 2016).

2017 SpaceX transformed its previously launched Falcon 9 rocket for reusability test into orbital flights (Graham, 2017). The parliament of Luxembourg recognized an act which will serve as a foundation stone for commercial exploitation of space minerals on July 13, 2017 (Jamasmie, 2017).

2018 The Electron rocket by Rocket Lab reached the orbit upon being launched for a second time from the Northern Island in New Zealand (Gugliotta, 2018).

2020 SpaceX became the first private enterprise to launch a manned rocket into space when it launched Falcon 9 with a Crew Demo space capsule (Mills, 2020). On November 15, 2020 SpaceX sent four astronauts into space inside a Falcon 9 rocket (Carter, 2020). 
3. It facilitates other space activities

4. It is a direct expression of society's character

Till now, human space travel has only relied upon the conventional chemical rockets even for LEO (Low Earth Orbit). However, developing concepts like Space elevators can transform the scenario of space travel into coming decades by making it much more economical and accessible to the general public.

\subsection{Modern Scenario of Space Travel}

The first picture of modern space travel came into movement when Konstantin Tsiolkovsky introduced a driving rocket equation in 1903, which was a fundamental equation dictating velocity required to carry objects into space. Soon after Tsiolkovsky, Robert Hutching Goddard, an american engineer proposed the concept of liquid fuelled rockets which could lift humans to the celestial objects.

With new formulations and concepts that were being derived in the 20th century, Russia became the first country to place an artificial object into space, so-called Sputnik-1, in 1957. Soon after the launch of Sputnik-1, another breakthrough came from Russia when, Russian cosmonaut, Yuri Gagarin, became the first human to be in space at an altitude of $327 \mathrm{Km}$, in 1961. Yuri Gagarin has inspired the world in so many ways that just after 23 days of Gagarin in space, Alan B. Shephard became the first U.S astronaut to travel into space.

Another breakthrough in the chapter of Space travel took place when the Apollo-11 crewed mission became the first mission to transcend humans to the surface of moon in 1969, with Niel Armstrong becoming the first human to land on the surface of moon followed by Buzz Aldrin, having net worth of $\$ 152$ billion dollar of today's evaluation (Knapp, 2019). Till now, a total of six moon manned missions has been carried out by the U.S alone between 19691972.

After the end of the space race between the U.S and U.S.S.R human space travel became much more frequent and comfortable when nations like Japan, Canada, Europe, Russia, U.S started collaborative approaches for joint scientific experiments at ISS (International Space Station), flying at an altitude of $400 \mathrm{Km}$. As of May 2020, approximately 99 crewed missions made it to the ISS using conventional chemical rockets, most of which is facilitated by ROSCOSMOS (Russian Federal Space Agency), NASA (National Aeronautics and Space Administration), and a few by SpaceX.

Till now the summary has briefed the history of the space travel of astronauts and cosmonauts by government funded space agencies along with the few ancient methods of space travel. However, the space tourism which is a rich part of the diverse space travel came into picture in the early 90's when a Russian company Mir Corp. in collaboration with American company Space Adventure Limited fled their first customer, Dennis Tito on 7 day trip to ISS ( International Space Station) using Soyuz spacecraft

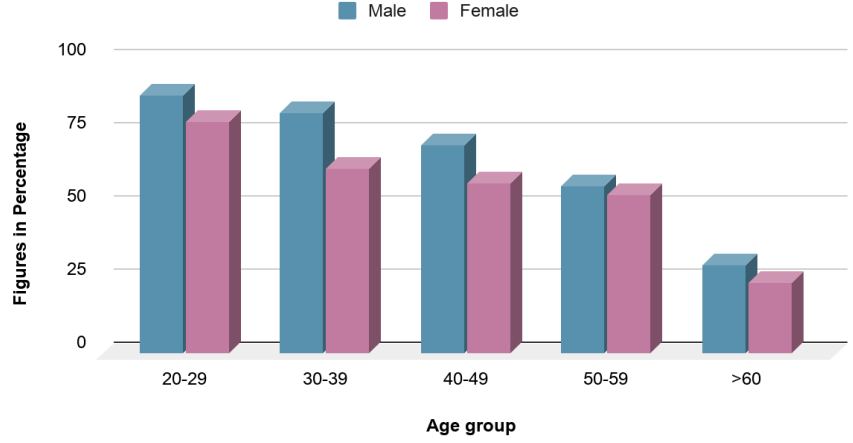

Figure 1. Demographics of interested candidates in Space tourism as per their Age group and Gender in U.S.A (http:// www.spacefuture.com/archive/space_tourism_market_demand_and_the_transportation_infrastructure.shtml)

used in 2001, at a cost of 20 million dollars. Soon after the trip of Tito, as a first commercial traveller, other millionaires like Mark Shuttleworth, Gregory Olsen, Anousheh Ansari, Richard Garriott, Guy Laliberte joined his company of becoming first few commercial space travellers in 2002, 2005, 2006, 2008, and 2009 respectively (Seedhouse, 2020).

Figure 1 represents a demographics of interest level of several groups of people, in the U.S alone, who wish to travel in space. It can be noted that the enthusiasm of space travel is well built at young age group people while significant enough for the people belonging to the age group of 60's or more. In one research study it has been found that people are comfortable to spend their 1 year's salary or more for just one suborbital space trip, indicating the excitement among the general public for space trips.

Till now, human space travel has only relied upon the conventional chemical rockets even for LEO (Low Earth Orbit). However, developing concepts like Space elevators can transform the scenario of space travel into coming decades by making it much more economical and accessible to the general public.

\section{Space Tourism}

The above sections have introduced the historical background of Space travel, Industrial overview and their models for making space tourism into reality. But what exactly is Space tourism, and how concept office Space tourism is evolving? This section will solely try to explain the concept of Space tourism along with its subtypes.

\subsection{What is Space Tourism \& Its Dawn}

Space tourism is a commercial service provided by government funded or private entities to their customers for their travel into space for a varisities of purposes. ie. leisure, business, and research. The idea of modern space tourism first got into picture in early 1970 with the concept of Space Shuttle, which was originally intended to design to carry 74 passengers into orbit along with the necessary construction and research payload for the early Space Station (Stimac, 2020). The concept of Shuttle design follows the idea to carry citizens, other than astronauts, in suborbital space. However, the idea to 
carry passengers through shuttle got stalled after the Challenger disaster in 1986.

Following the collaboration of Mircorp with Space Adventures Ltd. in 1990, Dennis Tito became the first commercial Citizen, by having his trip to ISS. As the concept of Space tourism started to get global attention, the image of Space tourism started to get broadened among public and industries.

\subsection{Types of Space Tourism}

As a result of which Space tourism has been divided into its sub categories (Yuhas, 2017).

Firstly, sub orbital space tourism: The commercial space activity which involves the trajectory of a spaceship carrying tourists to intersect the earth's atmosphere. This type of tourism activity will be commercially rolled out by the Virgin Galactic in coming years, above the Karman line, which will be dedicated to give tourists a feel of weightlessness, high speed experience, and providing them a view of Earth curvature. In such commercial activity, spacecraft will not make a complete revolution and around the earth's orbit.

Secondly, orbital space tourism: This type of Space tourism activity can be comprehended as a commercial activity that seeks tourists an ability to experience a loop around earth's orbit. Space Adventures Ltd has been the only industry in coordination with Mir Corp. to send tourists into ISS for recreational purposes at a cost of 20 million dollar.

Thirdly, tourism beyond Earth: Any commercial activity which seeks to provide tourists an experience beyond the earth's orbit, lies in this category. This type of tourism first got its global attention when the Space Adventures Ltd. proposed its plan for providing its customer a visiting loop around the lunar Orbit at the cost of 100 million dollar in 2007. Recently in 2017, SpaceX has also announced its plan to carry its tourists around the lunar Orbit using its Starship concept at a cost of $\$ 70$ million dollar.

From the above section, it is clear that with growing interest in tourism among public and industries, the concept of space tourism is evolving with time. And with such large investment by industries, businessmen, and entrepreneurs alone in the space tourism sector, the commercial activity into the earth's orbit and beyond is highly anticipated in the coming decades.

\section{Initiative \& Innovation}

With the evolution of several government space agencies in different nations, private giants like SpaceX, Virgin Galactic, Blue origin and many others started to appear across the several nations. This section will particularly narrow down our focus of discussion over two emerging space giants, SpaceX and Virgin Galactic. Founded in 2002, SpaceX has a current net worth of 15.3 billion dollar (Huddleston Jr, 2020). SpaceX, which is recognised for providing the affordable commercial services of launching payloads to ISS and NEO (Near Earth orbit) and, as a first private industry to launch astronauts from the american soil using its reusable rocket, first entered into the arena with its Falcon 1 rocket in 2008 (Eldrige, 2020). On the other hand, Virgin Galactic was first founded in 2004, with Richard Branson itself as founder of the company, and has a net worth of 4.8 billion dollar, as of November 2020 (Dawkins, 2020). Virgin Galactic, unlike public space agencies, is profoundly known for providing and developing commercial space flight for tourists at affordable cost.

With these two giants into the field, gaining the popularity among the general public, shares a common intent of making space travel widely accessible at the affordable cost.

SpaceX and Virgin Galactic are relying on their own business model and innovation for making space travel accessible at lower price as possible. The development of of the reusable rocket by SpaceX hasn't only cut the cost of the commercial rocket launch by $\$ 200.000$ to $\$ 300.000$, but also the use of 3D printing technology for manufacturing of rocket parts has reduced the overall cost of the commercial flight to ISS and the satellite launch by approximately $\$ 10,000 /$ kilogram as compared to its public founded competitor like Boeing and Lockheed Martin (Jorge, 2015). Such developing models have not only paved the path for cheaper spaceflight but also so for a reliable one.

Virgin Galactic on other hand, continued its goal of space tourism by evolvingits fleet. (i.eSpaceShipTwo) SpaceShipTwo, a precursor of SpaceShipOne, which may begin the era of commercial space tourism in the coming years. Assisted with two twin- hulled aircraft carriers, so-called Whiteknight, SpaceShipTwo will detach from them at altitude of $15 \mathrm{Km}$, which will be then propelled and maneuvered further 100 $\mathrm{km}$ into space, to provide their customer a taste of weightlessness (Hollingham, 2016). Currently, SpaceShipTwo is designed to carry 6 tourists along with pilot and copilot up to an altitude of $100 \mathrm{Km}$.

Not to mention, both Industries have faced a series of setbacks after their establishment but, the idea to provide an access of space to a larger group of audience has motivated these companies to move on and provide a reliable spaceflight. As John Gedmark, executive director of commercial flight says, "There is never going to be such a thing as perfectly safe spaceflight, but they're going to get as safe as they possibly can" (Howell, 2019).

With a continuous development in the cost reduction \& progressive technology, the charges of a commercial space flight is expected by Virgin Galactic per tourist to be $\$ 250.000$ way beyond the general public's reach. To make space approachable to a wider customer, these corporations need to come up with unique inducing strategies and ideas, which could ensure the company's goals along with their profit in the market.

Both the company sees a foreseeable vision of 


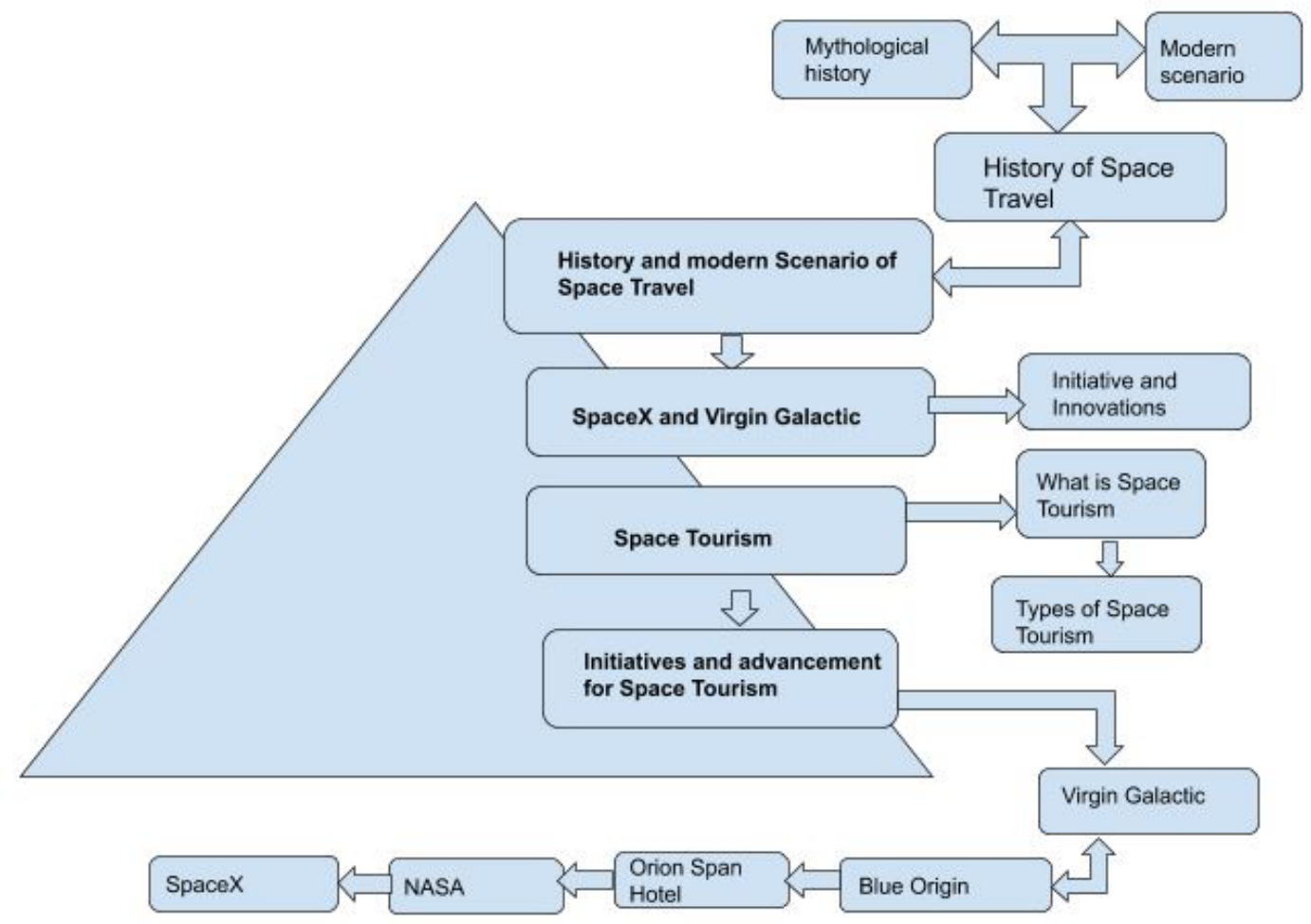

Figure 2. Space tourism roadmap (Authors' own design)

providing mankind a new possible perspective of seeing their existence in space either by making them an interplanetary species or by giving them a flavour of being a space tourist. SpaceX has its ultimate goal of making sustainable living in space and making mankind an interplanetary species. Also, the company has unveiled its deal with space tourism company- Space Adventures Ltd., to launch four passengers into Earth's orbit using Falcon 9 rocket and then their return back using Dragon capsule (Malik, 2020). However, for such a journey, the company hasn't revealed its price tag for Dragon crew tourists, but it is approximated to be in range of charge proposed by other commercial space flights. Recently, the company has agreed to push the idea of space tourism by arranging a journey around the Moon's orbit for its customers using its Starship and then return back down to earth (Wroth, 2019).

Similarly, Virgin Galactic with their goal of inspiring the future generations and making space accessible to the general public by the concept of Space tourism, has already received an application of 8,000 interested candidates, ready to spend $\$ 250,000$ for their sub-orbital flight experience. Company, as of March 2020 has received 20 of 29 approvals from FAA to conduct its space tourism activity. To promote Space tourism, Virgin Galactic has built its terminal, so- called Spaceport in New Mexico as a functional launchpad for all Galactic flights (Peterson, 2020). However, until now, neither SpaceX nor Virgin Galactic has been able to make commercial space tourism possible, besides their crewed flight testing. Even if space tourism gets possible by these two giants in coming years, it seems that only a few handful of the people will be able to taste the weightlessness in the suborbital flights, due to the lavish charge of conventional space travel.

As suborbital tourism is getting the public attention, more and more industries are approaching for public interest in the space tourism. i.e Blue origin which is a private aerospace industry, cofounded by Jeff Bezos is currently developing its New Shepard spacecraft for providing its customer a vertical takeoff and landing experience into the suborbital space. Space Adventures Ltd. has taken the concept of space tourism to a new extent by offering its customer a tour around the orbit of the moon using the conventional Soyuz spacecraft at a fee of $\$ 1000,000$ dollar (Than, 2005).

From the above section, it is clear that making space accessible to everyone by using high cost conventional rockets is an impossible task, even for corporations like SpaceX, Virgin Galactic, and Blue origin. In order to make space travel possible for a wider group of audience, not limited to billionaires, these cooperatives need to come up with new revolutionary ideas which could bring down the cost of space travel within the economy of a larger section of people.

\section{Current Initiative and Advancements for Making Space Tourism Possible}

There are different projects for space travel right now. Three private enterprises called Virgin Galactic, Blue Origin and Orion Span Hotel are planning to offer trips around Earth's orbit. NASA, a governmental organization, wants to select astronauts to start a colony on the Red Planet and SpaceX to organize touristic trips to Mars (Neagu, 2018).

From the above figure, a forecast by market researchers for the Space tourism market has been developed in which predicted revenue of the Space 


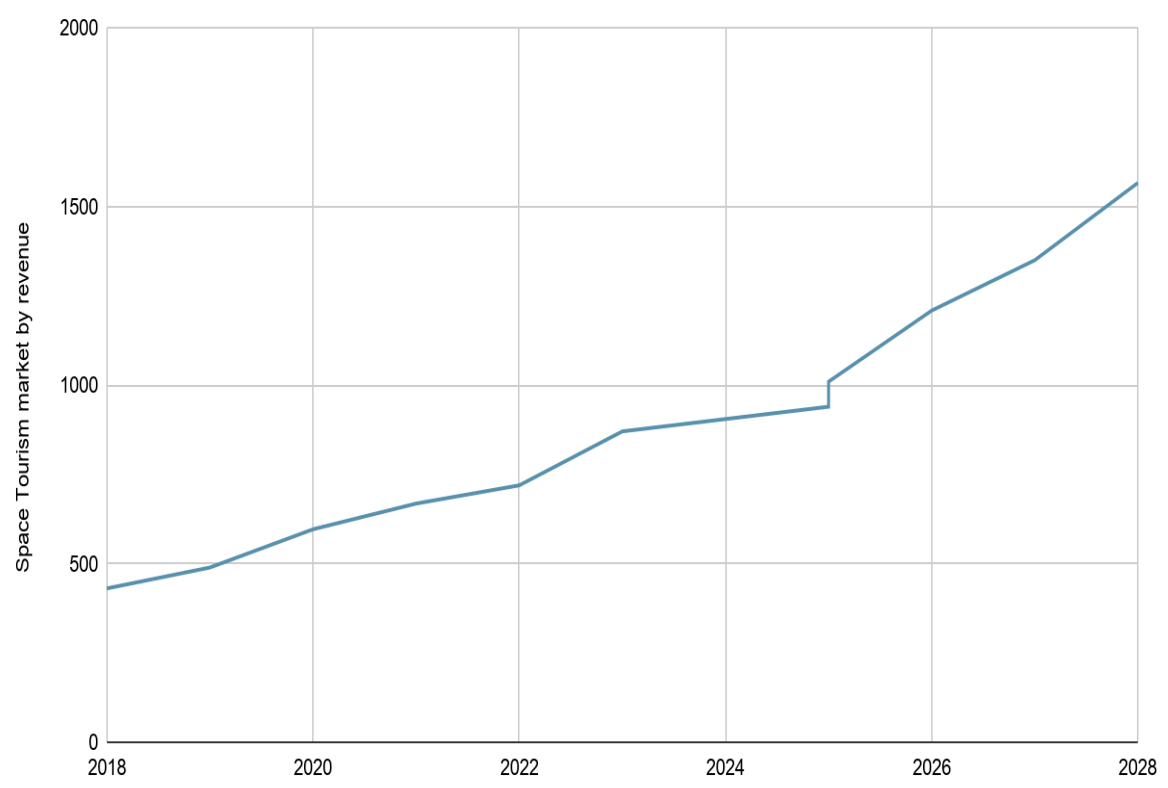

Figure 3. Shows a forecasted model for Space tourism market revenue ("Global Space Tourism Market...", 2020).

tourism market as of 2018 was around $\$ 435.1 \mathrm{Mn}$ and is expected to increase to about $\$ 1,566.5 \mathrm{Mn}$ by 2028 , increased by more than $\$ 1,000 \mathrm{Mn}$ in just a period of 10 years.

\subsection{Virgin Galactic}

Virgin Galactic is a commercial space line with an objective of providing a new perspective of our planet, inspiring future generations, exploring our universe and creating a better future for our community and planet (Virgin Galactic, 2020). The initiative founded by Richard Branson - a British entrepreneur - received some 8000 online booking orders and stated that the demand was on the rise. The company also stated that they received more than 600 reservation requests from the clients of Future Astronaut in 60 countries (Thorbecke, 2020). Planned flight stages include a shuttle detaching from the mothership after a certain altitude and the use of a rocket to push the mothership into the sub orbit (Davidian, 2020).

\subsection{Blue Origin}

Blue Origin, an organization founded by Amazon's CEO Jeff Bezos, is getting ready to do its first test flight by launching a rocket from the test zone in Western Texas into the edge of Earth's atmosphere. Blue Origin wants to send its customers to brief entertainment tours in space. However, the company has not started selling the tickets yet. Nor has it announced the fees (Wattles, 2020).

\subsection{Orion Span Hotel}

Well-heeled space tourists will have a new orbital destination four years from now, if one company's plans come to fruition. The founder and CEO of Orion Span, Frank Burger said that: "We start the first affordable luxurious space hotel ever". The cost of accommodating in Aurora Station for 12 days will cost 9.5 billion dollars at least (Wall, 2018). Aurora
Station designed for space tourism will include spacious interior for easy mobility, large observation windows, personal sleep pods, exquisite meals, and plenty of activity areas (Orion Span, 2019).

\subsection{NASA}

NASA was founded on October 1, 1958 as a part of the US government and ever since, it has overseen space-related and aviation-related science and Technologies in the U.S (NASA, 2018).

NASA also declared that it was planning to maket o Space Station available for space tourism. It is expected to have a 30-day tour twice a year. The tour fee is expected to be 39 million pounds and the accommodation fee per night is assumed to be 27.000 pound per night (Harley, 2019). Among is Moon exploration plans, NASA continues its low orbit studies and tests. Besides, the organization will cooperate with private sectors to train the astronauts and to maket he space economy stronger (NASA, 2019).

Once the Mars trip is successfully launched into the market and astronauts are safely returned home, NASA expects to see more innovations in its explorations by 2021. NASA plans to send the first woman and the next man onto the Moon and to see some sustainable explorations as a part of the Artemis programme - a programme getting ready for Mars exploration- in 2024 (NASA, 2020).

\subsection{SpaceX}

SpaceX is an organization with worldwide recognition and a milestone in the space industry as the sole private enterprise bringing back a space shuttle from the Earth's orbit in 2010. SpaceX currently works on rocket technologies. It successfully launched Falcon Heavy in 2018. It has been currently working on the most powerful and new generation launch tools ever to carry man to Mars (Yazici and Darici, 2019). Its Starship 
system represents a reusable transportation to serve in extra-terrestrial missions (SpaceX, 2020). Commercial satellite companies have been pleased with SpaceX's initiative to create reusable rockets, as it will lower the costs. This business model of SpaceX forced governments and commercial launching operators to change their conventional opinion (Reddy, 2018). Elon Musk announced that he was going to send three tourists into space for a 10-day trip to the Space Station and the one-way ticket will cost 55 million dollars. Unlike other vehicles in tourism transportation, design, and manufacturing, Crew Dragon will be the first official human flighy to be considered, safe, classified, and officially approved according to NASA criteria. SpaceX also collaborates with Space Adventures to send up to four private citizens. In 2018, the first civilian passenger - a billionaire in Japan, paid in advance for his trip to the Moon inside a tourist craft, rented for a loop, and SpaceX plans to start this trip in 2023 (King, 2020).

\section{Conclusion}

Space giants like SpaceX, Virgin Galactic, Blue Origin, Orion Span, and many others are taking new initiatives to start a new chapter in the field of space activities by introducing the concept of Space tourism to the general public. However, with the existing proposed by these corporations it seems only a handful of the people will be able to join the elite company of Dennis Tito and few others. To make space travel accessible for diverse communities, these corporations need to implement and invest in new innovative ideas.

In this article, a review was carried out on defining goals of Space tourism, history of human space travel, and initiatives thus being developed by different corporations for making commercial space travel possible. In this article, the definition of Space tourism has also been broadened into its three sub categories namely, Sub-orbital space tourism, Orbital space tourism, and Tourism beyond earths' orbit, in which corporations like SpaceX and Space Adventures Ltd are pushing their limits to plan a commercial visit around lunar orbit but at significant cost.

In the early 70's, after the first time when the concept of modern Space tourism was coined, a significant amount of development has been in the sector of Space tourism alone. However, still Space tourism is at its infancy stage, where much more development needs to be done. With the application of conventional chemical rockets, it has been noted that space travel could only be offered to a few of handful people due to its deluxe charges. To eliminate such problems, corporations need to start working on an alternative option, which could not only make space travel a reliable but also cheaper one. Construction and application of Space elevators for the purpose of space tourism may be a viable substitute.

\section{References}

Annadurai, M. Krishnan, A. Kannan, S. A. and Rama Murali, G. K. (2011). Commercial Space Travel and Space Tourism, National Conference on Space Transportation Systems (STS-2011): Opportunities and Challenges. Bangalore, India: ISRO Satellite Centre.

Ashford, D. and Collins, P. (1990). Your Spaceflight Manual: How You Could be a Tourist in Space Within Twenty Years. London: Simon and Schuster Inc.

Carter, J. (November 13, 2020). How You Can Watch Online This Weekend As NASA And SpaceX Launch Four Astronauts On 'Resilience' Spacecraft, Forbes. Retrieved from: https://www.forbes.com/ sites/jamiecartereurope/2020/11/13/how-youcan-watch-online-this-weekend-as-nasa-andspacex-launch-four-astronauts-on-resiliencespacecraft/?sh=73e087363b12.

Chang, Y. W. (2015). The first decade of commercial space tourism. Acta Astronautica, 108, 79-91. http://dx.doi. org/10.1016/j.actaastro.2014.12.004

Civelek, M. and Türkay, O. (2019). Uzay Turizmine Iliş̧kin Uluslararası Turizm Karikatürlerinin Göstergebilimsel Bir Analizi. Afyon Kocatepe Üniversitesi Sosyal Bilimler Dergisi, 21 (3), 960-980.

Clark, S. (September 28, 2008). Sweet success at last for Falcon 1 rocket, Spaceflight Now. Retrieved from: https://spaceflightnow.com/falcon/004/.

Clark, S. (October 25, 2014). First commercial mission to the moon launched from China, Spaceflight Now. Retrieved from: https://spaceflightnow.com/2014/10/25/firstcommercial-mission-to-the-moon-launched-fromchina/.

Coren, M. (July 14, 2004). Private craft soars into space, history, CNN. Retrieved from: https://edition.cnn. com/2004/TECH/space/06/21/suborbital.test/.

Danov, D. G. (2020). A Review of Space Tourism Services: Supply and Demand Challenges. Journal of Tourism Leisure and Hospitality, 2(1): 29-35.

Dawkins, D. (November 16, 2020). Richard Branson's Net Worth Plunges $\$ 200$ Million As Pandemic Grounds Virgin Galactic Spaceflight, Forbes. Retrieved from: https:// www.forbes.com/sites/daviddawkins/2020/11/16/ richard-bransons-net-worth-plunges-200million-as-pandemic-grounds-virgin-galacticspaceflight/?sh=2b92b46814d1.

Davidian, K. (2020). Space Tourism Industry Emergence: Description and Data. New Space, 8 (2), 87-102.

Eldridge, A. (November 12, 2020). SpaceX, Britannica. Retrieved from: https://www.britannica.com/topic/ SpaceX.

Eilingsfeld, F. and Abitzsch, S. (1993). Space tourism for Europe: a case study. Space Future, Paper no. IAA.1.293-654, 44th IAC, Graz, Austria, 16-22 October.

Foust, J. (November 24, 2015). Blue Origin Flies - and Lands - New Shepard Suborbital Spacecraft, Space News. Retrieved from: https://spacenews.com/blue-originsuccessfully-flies-new-shepard-suborbital-vehicle/.

Gainor, C. (2008). To a Distant Day: The Rocket Pioneers. Lincoln, NE.: University of Nebraska Press.

Goswami, A. (April 02, 2017). Space journeys in ancient India, The Pioneer. Retrieved from: https://www.dailypioneer. 
com/2017/sunday-edition/space-journeys-in-ancientindia.html.

Graham, W. (March 30, 2017). SpaceX conducts historic Flacon 9 re-flight with SES-10-lands booster again, NASA Spaceflight. Retrieved from: https://www. nasaspaceflight.com/2017/03/spacex-historic-falcon-9re-flight-ses-10/.

Grush, L. (Nowember 16, 2015). Private space companies avoid FAA oversight again, with congress'blessing, The Verge. Retrieved from: https://www.theverge. com/2015/11/16/9744298/private-space-governmentregulation-spacex-asteroid-mining.

Gugliotta, G. (April 2018). Small Rockets Aim for a Big Market, Air Space. Retrieved from: https://www.airspacemag. com/as-next/milestone-180968351/.

Harding, P. (May 28, 2016). ISS controllers complete BEAM module expansion, NASA spaceflight.com. Retrieved from: https://www.nasaspaceflight.com/2016/05/issinflatable-module-beam-expansion/.

Harley, N. (June 7, 2019). NASA to open International Space Station to tourists from 2020, N World. Retrieved from: https://www.thenationalnews.com/world/ nasa-to-open-international-space-station-to-touristsfrom-2020-1.871745\#: : text $=$ Nasa $\% 20$ has $\% 20$ announced\%20it\%20will,of\%20up\%20to\%2030\%20 days.\&text=The $\% 20$ space $\% 20$ agency\%20recently\%20 announced,the\%20first\%20person\%20in\%20decades.

HobbySpace. (2014). A short history of private space development, Retrieved from: https://www. hobbyspace.com/NewSpace/history.html.

Hollingham, R. (April 22, 2016). What's the best (and cheapest) way to take a trip to space?, $B B C$ Future. Retrieved from: https://www.bbc.com/future/ article/20160422-whats-the-best-and-cheapest-wayto-take-a-trip-to-space.

Howell, E. (March 05, 2019). SpaceShipTwo: On a Flight Path to Space Tourism, Space.com. Retrieved from: https:// www.space.com/19021-spaceshiptwo.html.

Huddleston Jr, T. (August 18, 2020). How Tesla and SpaceX CEO Elon Musk spends his billions, CNBC Make it. Retrieved from: https://www.cnbc.com/2020/08/18/ how-tesla-and-spacex-ceo-elon-musk-spends-hisbillions.html.

Jamasmie, C. (July 13, 2017). Luxembourg becomes first European country to pass space mining law, Mining.com Retrieved from: http://www.mining.com/luxembourgbecomes-first-european-country-pass-space-mininglaw/.

Jorge, A. (December 7, 2015). SpaceX-Lowering the Cost of Access to Space, Digital Initiative. Retrieved from: https://digital.hbs.edu/platform-rctom/submission/ spacex-lowering-the-cost-of-access-to-space/.

King, A. K. (August 28, 2020). The Future of Space Tourism, Congressional Research Service. Retrived from: https:// fas.org/sgp/crs/space/R46500.pdf.

Knapp, A. (July 20, 2019). Apollo 11's 50th Anniversary: The Facts And Figures Behind The \$152 Billion Moon Landing, Forbes, https://www.forbes.com/sites/ alexknapp/2019/07/20/apollo-11-facts-figuresbusiness/?sh=446c72523377 Accessed:15.11.2020.

Mills, D. (May 30, 2020). SpaceX Launch: Highlights From NASA Astronauts' Trip to Orbit, The New York Times, Retrieved from: https://www.nytimes.com/2020/05/30/science/ spacex-launch-nasa.html Accessed: 03.11.2020.

NASA. (September 24, 2018). What Is NASA?. Retrieved from: https://www.nasa.gov/audience/forstudents/k-4/ stories/nasa-knows/what-is-nasa-k4.html Accessed: 16.11.2020.

NASA. (June 07, 2019). NASA Opens International Space Station to New Commercial Opportunities, Private Astronauts. Retrieved from: https://www.nasa.gov/ press-release/nasa-opens-international-space-stationto-new-commercial-opportunities-private. Accessed: 16.11.2020.

NASA. (August 10, 2020). NASA Perseveres Through Pandemic, Looks Ahead in 2020, 2021. Retrieved from: https://www.nasa.gov/feature/nasa-perseveresthrough-pandemic-looks-ahead-in-2020-2021 Accessed: 16.11.2020.

Neagu, A. L. (2018). Space Tourism: A new way of tourism not so distant in time or space (Unpublished Masters Thesis). Valencia: Universitat Jaume I.

Malik, T. (February 18, 2020). SpaceX will fly space tourists on Crew Dragon for Space Adventures, Space.com, Retrieved from: https://www.space.com/spacexcrew-dragon-will-fly-space-tourists.html Accessed: 18.11.2020.

Orion Span. (2019). A New Destination. Retrieved from: https://www.orionspan.com/tourism.

Pásková, M., Budinská, N. and Zelenka, J. (2021). AstrotourismExceeding Limits of the Earth and Tourism Definitions? Sustainability, 13, 373. DOI: https://doi.org/10.3390/ su13010373

Peterson, B. (March 04, 2020). Space Tourism Set to Take Off in 2020, Says Virgin Galactic CEO, Travelmarket Report, Retrieved from: https://www.travelmarketreport.com/ articles/Space-Tourism-Set-to-Take-Off-in-2020-SaysVirgin-Galactic-CEO Accessed:20.11.2020.

Reddy, V. S. (2018). The SpaceX Effect. New Space, 6 (2). DOI: 10.1089 /space.2017.0032.

Rhian, J. (January 22, 2016). Blue Origin Re-Flies New Shepard Used On Nov.2015 Flight, Spacelight Insider. Retrieved from: https://www.spaceflightinsider.com/missions/ commercial/blue-origin-re-flies-new-shepard/.

Seedhouse, E. (March 30, 2020). Space Tourism, Encyclopædia Britannica. Retrieved from: https://www.britannica. com/topic/space-tourism.

Spaceref. (June 15, 2000). Soyuz TM-30 Return-to-Earth Timeline. Retrieved from: http://www.spaceref.com/ news/viewsr.html?pid=495.

Space Frontier Foundation. (May 19, 2004). Go GoFast! Space Frontier Foundation Congratulates First Amateur Team to EnterSpace. Retrievedfrom:http://archive.spacefrontier. org/PressReleases/2004/20040519gofastflight.html Accessed: 02.11.2020.

SpaceX. (March 2020). Starship Users Guide. Retrieved from: https://www.spacex.com/media/starship_users_ guide_v1.pdf.

Stimac, V. (July 5, 2020). A Definite History of Space Tourism \& Human Spaceflight, Space Tourism Guide. Retrieved from: https://spacetourismguide.com/history-ofspace-tourism/.

Virgin Galactic. (2020). Who We Are. Retrieved from: https:// www.virgingalactic.com/who-we-are/. 
Yazici, A.M. and Darıcı, S. (2019). The New Opportunities in Space Economy. Insan ve Toplum Bilimleri Araştırmaları Dergisi, 8 (4): 3252- 3271.

Yazici, A.M. (2020). An Investigation on The Economic Feasibility of Space Elevator. Havacılık ve Uzay Çalışmaları Dergisi, 1(1), 33-47.

Yuhas, A. (February 28, 2017). SpaceX to send two people around the moon who paid for a 2018 private mission, The Guardion. Retrieved from: https://www. theguardian.com/science/2017/feb/27/spacex-moonprivate-mission-2018-elon-musk.

Than, K. (August 10, 2005). Space Adventures Offers Up the Moon for Future Tourists, Space.com. Retrieved from: https://www.space.com/1425-space-adventuresoffers-moon-future-tourists.html Accessed: 20.11.2020.

The Telegraph. (May 22, 2012). SpaceX becomes first private firm to launch craft to space station. Retrieved from: https://www.telegraph.co.uk/news/science/ space/9281509/SpaceX-becomes-first-private-firm-tolaunch-craft-to-space-station.html.

Thorbecke, C. (February 26, 2020). Virgin Galactic to resume selling tickets to space, reports skyrocketing demand, $A B C$ News. Retrieved from: https://abcnews.go.com/ Business/virgin-galactic-resume-selling-tickets-spacereports-skyrocketing/story?id=69229936.

Wall, M. (April 27, 2011). First Space Tourist: How a U.S. Millionaire Bought a Ticket to Orbit, Space.com. Retrieved from: https://www.space.com/11492-spacetourism-pioneer-dennis-tito.html.

Wall, M. (April 05, 2018). Luxury Space Hotel to Launch in 2021, Space.com. Retrieved from: https://www.space. com/40207-space-hotel-launch-2021-aurora-station. html.

Wattles, J. (October 14, 2020). Jeff Bezo's rocket company launches first test of its tourism spaceship in a year, CNN Business. Retrieved from: https://edition.cnn. com/2020/10/14/tech/blue-origin-new-shepard-testlaunch-scn/index.html.

Wroth, C. (September 29, 2019). Elon Musk Unveils SpaceX New Starship, Designed To Fly To The Moon, Mars and Beyond, NPR. Retrieved from: https://www.npr. org/2019/09/29/765526405/elon-musk-unveilsspacexs-new-starship-designed-to-fly-to-the-moonmars-and-beyo.

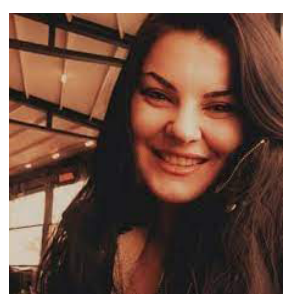

Ayşe Meriç Yazıcı was born on January 1, 1985. She is a PhD candidate at Istanbul Aydin University, Department of Business. She is also a Visiting Scholar at the Blue Marble Space Institute of Science (BMSIS). She works in the fields of space economics, space technologies, astropolitics and biomimicry. She is fluent in English and Russian.

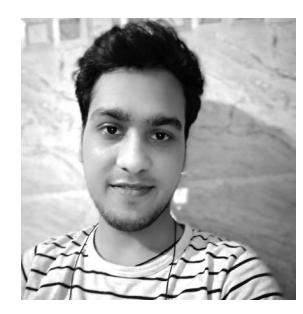

Born on February, 15, 1998, Satyam Tiwari has done his graduation from Kurukshetra University in Department of Aeronautical Engineering in year 2020. During his academic session, he has done his training work with Air India and research work on miniature satellites and model rockets as part of his internship program. Currently Satyam is a Visiting Scholar at the Blue Marble Space Institute of Science (BMSIS). Besides his academic career, he is learning and exploring the domain of Astronomy/ Astrophysics.

ORCID: 0000-0001-7507-6921 